\title{
Induction of adipose-derived stem cells into Schwann-like cells and observation of Schwann-like cell proliferation
}

\author{
XIUMEI FU ${ }^{1,2}$, ZHAOXUE TONG ${ }^{1}$, QI LI ${ }^{3}$, QINGFEI NIU ${ }^{3}$, ZHE ZHANG ${ }^{1}$, \\ XIAOJIE TONG ${ }^{1}$, LEI TONG ${ }^{1}$ and XU ZHANG $^{1}$ \\ ${ }^{1}$ Department of Anatomy, College of Basic Medical Sciences, China Medical University, Shenyang, Liaoning 110001; \\ ${ }^{2}$ Department of Anatomy, College of Basic Medical Sciences, Chengde Medical College, Chengde, Hebei 067000; \\ ${ }^{3}$ Department of Hand Surgery, Affiliated Feng Tian Hospital, Shenyang Medical College, \\ Shenyang, Liaoning 110001, P.R. China
}

Received August 21, 2015; Accepted May 21, 2016

DOI: $10.3892 / \mathrm{mmr} .2016 .5367$

\begin{abstract}
The peripheral nervous system has the potential for full regeneration following injury and recovery, predominantly controlled by Schwann cells (SCs). Therefore, obtaining a sufficient number of SCs in a short duration is crucial. In the present study, rat adipose-derived stem cells (ADSCs) were isolated and cultured, following which characterization of the ADSCs was performed using flow cytometry. The results showed that the cells were positive for the CD29 and CD44 markers, and negative for the CD31, CD45, CD49 and CD106 markers. The multilineage differentiation potential of the ADSCs was assayed by determining the ability of the cells to differentiate into osteoblasts and adipocytes. Following this, the ADSCs were treated with a specific medium and differentiated into Schwann-like cells. Immunofluorescence, western blot and reverse transcription-quantitative polymerase chain reaction analyses showed that $\sim 95 \%$ of the differentiated cells expressed glial fibrillary acidic protein, S100 and p75. In addition, the present study found that a substantial number of SCs can be produced in a short duration via the mitotic feature of Schwann-like cells. These data indicated that Schwann-like cells derived from ADSCs can undergo mitotic proliferation, which may be beneficial for the treatment of peripheral nerve injury in the future.
\end{abstract}

\section{Introduction}

Schwann cells (SCs) are the predominant cell type constituting the structure of peripheral nerves, and are crucial in repair

Correspondence to: Professor Xiaojie Tong, Department of Anatomy, College of Basic Medical Sciences, China Medical University, 77 Puhe Road, Shenbei New Area, Shenyang, Liaoning 110001, P.R. China

E-mail: txjcmu@aliyun.com.cn

Key words: rat adipose-derived stem cells, Schwann-like cells, glial fibrillary acidic protein, S100, P75, proliferation and regeneration following peripheral nerve injury (PNI) (1). Following PNI, SCs can activate macrophages to remove necrotic debris in the early stage, and provide a channel for regeneration (2). SCs not only form the Büngner band to guide axonal regeneration, they also secrete neurotrophic factors, extracellular matrix and cell adhesion molecules to promote nerve regeneration (3). However, autologous SCs are difficult to obtain and expand to sufficient numbers in a short duration; this is due to limitations in tissue availability, morbidity of the donor site and the sacrifice one or more functioning nerves with consequential loss of sensation (4). The ideal features of transplantable cells are that they are readily available, proliferate rapidly in vitro and have characteristics of low or no immunogenicity.

Mesenchymal stem cells (MSCs) are an attractive cell source for the regeneration of nerve tissue due to their self-renewal ability, high growth rate and multipotent differentiation properties (5). Bone marrow-derived mesenchymal stem cells (BMMSCs) can differentiate into an SC phenotype (6), as well as express myelin-associated markers and remyelinate when transplanted into injured sciatic nerves of rats (7). However, the isolation of BMMSCs is an invasive and painful procedure, and the ratio of MSCs in the bone marrow is relatively low $(<1 / 100,000)(8)$. Therefore, an alternative cell source is in urgent demand. Adipose-derived stem cells (ADSCs) have similar phenotypic and gene expression profiles to BMMSCs. ADSCs also have unique advantages: They can be readily harvested using a safe and conventional liposuction procedure from subcutaneous fat tissue; the ratio of ADSCs in adipose tissue is higher than in BMMSCs ( 1-2\%); and ADSCs proliferate significantly faster than BMMSCs (9). It has also been reported that ADSCs can be transdifferentiated to exhibit an SC phenotype (10).

In the present study, the transdifferentiation of rat ADSCs into Schwann-like cells was performed, and immunofluorescence, western blot and reverse transcription-quantitative polymerase chain reaction (RT-qPCR) experiments were performed to detect glial fibrillary acidic protein (GFAP), S100 and p75. The mitotic feature of Schwann-like cells was also assessed. The present study aimed to provide a foundation for future experiments regarding the suitable selection of seed cells for nerve tissue engineering in the treatment of PNI. 


\section{Materials and methods}

Animals. A total of four male Wistar rats (age, 3-4 weeks) were obtained from the Experimental Animal Centre of China Medical University (Shenyang, China; no. SYXK Liao 2013-0001). The rats were housed in plastic cages at $24^{\circ} \mathrm{C}, 50 \%$ humidity, under a 12-h light/dark cycle with access to food and water ad libitum. In the present study, the mice were anesthetized using $10 \%$ chloral hydrate $(350 \mathrm{~g} / \mathrm{kg})$ and sacrificed using chloral hydrate $(700 \mathrm{~g} / \mathrm{kg})$ following adipose tissue sampling. The study protocol was approved by the Animal Experimental Committee of the China Medical University.

ADSC isolation and culture. The ADSCs were carefully isolated from rat inguinal fat pads, dissected and minced under aseptic conditions. Subsequently, the tissue was enzymatically dissociated at $37^{\circ} \mathrm{C}$ for 60 min using $0.1 \%$ collagenase I (Invitrogen; Thermo Fisher Scientific, Inc.). The dissociated cells were cultured in Dulbecco's modified Eagle's medium/F12 (DMEM/F12; Genview, Tallahassee, FL, USA) containing $10 \%$ fetal bovine serum (FBS; Biological Industries, Kibbutz Beit Haemek, Israel) and 1\% (v/v) penicillin/streptomycin solution for $48 \mathrm{~h}$ at $37^{\circ} \mathrm{C}$ in $5 \% \mathrm{CO}_{2}$. The non-adherent cells were removed on replacement of the medium every 2-3 days when the cells reached $80 \%$ confluence.

ADSC multilineage differentiation potential. Rat ADSCs at the fourth passage were seeded into 6-well plates at a density of $1 \times 10^{5}$ cells $/ \mathrm{ml}$ and divided into experimental and control groups. Once the cells reached $80 \%$ confluence, the experimental group was cultured in induction medium. To induce osteogenic differentiation, the ADSCs were cultured at $37^{\circ} \mathrm{C}$ in 5\% $\mathrm{CO}_{2}$ for 28 days in DMEM/F12 supplemented with $10 \%$ FBS, $0.1 \mu \mathrm{M}$ dexamethasone, $10 \mu \mathrm{M} \beta$-glycerol phosphate and $50 \mu \mathrm{M}$ ascorbate, and calcium deposition was visualized by staining with Alizarin Red (Sigma-Aldrich, St. Louis, MO, USA). To induce adipogenic differentiation, the ADSCs were cultured for 14 days in DMEM/F12 supplemented with $10 \%$ FBS, $1 \mu \mathrm{M}$ dexamethasone, $5 \mu \mathrm{g} / \mathrm{ml}$ insulin, $0.5 \mathrm{mM}$ isobutylmethylxanthine (IBMX) and $100 \mu \mathrm{M}$ indomethacin, and adipogenesis was evaluated by observing the production of intracellular lip droplets, detected using Oil-Red O (Sigma-Aldrich) and observed with a Nikon Eclipse 80i microscope (Nikon Corporation, Toyko, Japan).

Characterization of ADSC surface molecules using flow cytometry. Rat ADSCs at the fourth passage were harvested by trypsinization, following which the cells were fixed in neutralized $4 \%$ paraformaldehyde for $30 \mathrm{~min}$ at a density of $1 \times 10^{6}$ cells $/ \mathrm{ml}$, and then incubated with the following antibodies: Hamster fluorescein isothiocyanate (FITC)-conjugated CD29 (1:100; cat. no. 11-0291), phycoerythrin (PE)-conjugated CD31 (1:100; cat. no. 25-0310), mouse FITC-conjugated CD45 (1:200; cat. no. 11-0461), mouse allophycocyanin-conjugated CD49 (1:50; cat. no. 17-1490) and mouse PE-conjugated CD44 (1:400; cat. no. 12-0444), from eBioscience, Inc. (San Diego, CA, USA), and mouse FITC-conjugated CD106 (1:100; BD Biosciences, Franklin Lakes, NJ, USA) at $4^{\circ} \mathrm{C}$ for $30 \mathrm{~min}$. The numbers of immunoreactive cells were detected using BD FACSDiva 7.0
(BD Biosciences), whereas cells stained with PBS $(0.01 \mathrm{M}$; $\mathrm{pH}$ 7.4) served as a control.

Induction of ADSCs into an SC phenotype. When the rat ADSCs in the fourth passage were subconfluent, the medium was replaced with fresh medium containing $1 \mathrm{mM} \beta$-mercaptoethanol ( $\beta$-ME; Sigma-Aldrich) for $24 \mathrm{~h}$. The cells were then cultured in DMEM/F12 supplemented with $10 \%$ FBS and $35 \mathrm{ng} / \mathrm{ml}$ alltrans-retinoic acid (Sigma-Aldrich) for $72 \mathrm{~h}$ at $37^{\circ} \mathrm{C}$ in $5 \% \mathrm{CO}_{2}$. Subsequently, the cells $\left(1 \times 10^{6}\right.$ cells $\left./ \mathrm{ml}\right)$ were incubated in SC-conditioned medium containing 10\% FBS, $14 \mu \mathrm{M}$ forskolin (FSK; Alexis Biochemichals, San Diego, CA, USA), $5 \mathrm{ng} / \mathrm{ml}$ platelet-derived growth factor-AA (PeproTech, Rocky Hill, NJ, USA), $10 \mathrm{ng} / \mathrm{ml}$ basic fibroblast growth factor (bFGF; PeproTech) and $200 \mathrm{ng} / \mathrm{ml}$ recombinant human heregulin- $\beta 1$ (HRG; PeproTech) for 12 days at $37^{\circ} \mathrm{C}$ in $5 \% \mathrm{CO}_{2}$. The cells were passaged with trypsin/EDTA when required, and fresh medium was added approximately every $72 \mathrm{~h}$.

\section{Identification of Schwann-like cells}

Immunofluorescence. For immunocytochemical assessment of the differentiated ADSC markers, the ADSCs were cultured in SC-conditioned medium for 12-14 days, and were then fixed in $4 \%(\mathrm{~W} / \mathrm{V})$ paraformaldehyde for $30 \mathrm{~min}$. The fixed cells were blocked with goat serum for $1 \mathrm{~h}$ at room temperature. The polyclonal primary antibodies, rabbit polyclonal GFAP (1:200; cat. no. sc-9065), S100 (1:200; cat. no. sc-28533) and p75 NGF receptor protein (P75, 1:200; cat. no. sc-5634), all from Santa Cruz Biotechnology, Inc. (Santa Cruz, CA, USA) were added and incubated at $4^{\circ} \mathrm{C}$ overnight. Following incubation, goat anti-rabbit Cy3- (1:100; cat. no. SA00003-2) or FITC-conjugated (1:100; cat. no. SA00009-2) secondary antibodies (Proteintech Group, Inc., Chicago, IL, USA) were added at $37^{\circ} \mathrm{C}$ for $1 \mathrm{~h}$. The cell nuclei were labeled using DAPI (Sigma-Aldrich). PBS was substituted for primary antibodies as a control. The cells were visualized and recorded using a fluorescence microscope (Nikon Eclipse 80i).

Western blot analysis. Rat ADSCs in the fourth passage were harvested by trypsinization, and $1 \times 10^{6}$ cells $/ \mathrm{ml}$ were fixed in $100 \mu \mathrm{l}$ protein isolation, followed by centrifugation at $12,000 \mathrm{~g}$ for $30 \mathrm{~min}$ at $4^{\circ} \mathrm{C}$. The cell lysates were analyzed using a commercial bicinchoninic acid assay kit (cat. no. BCA01; Beijing Dingguo Biotech, Co., Ltd. Beijing, China). A total of $30 \mu \mathrm{g}$ protein was prepared per sample, and denatured at $95^{\circ} \mathrm{C}$ for $5 \mathrm{~min}$. The proteins were resolved by 15 or $12 \%$ SDS-PAGE (Beijing Dingguo Biotech, Co., Ltd.) and transferred onto PVDF membranes. The membranes were blocked in $5 \%$ bovine serum albumin for $1 \mathrm{~h}$, and then incubated overnight at $4^{\circ} \mathrm{C}$ with GFAP, S100, P75 and GAPDH primary antibodies (1:10,000, Proteintech Group, Inc.). The membranes were then incubated with goat anti-mouse (cat. no. L3032-1/2) and anti-rabbit (cat. no. L3012-1/2) IgG-horseradish peroxidase-conjugated secondary antibodies $(1: 10,000$; Signalway Antibody, College Park, MD, USA) for $1 \mathrm{~h}$ at $37^{\circ} \mathrm{C}$. The blots were scanned using a ChemiDoc XRS+ image analysis system (Bio-Rad Laboratories, Inc., Hercules, CA, USA) and analyzed using Image J software (National Institutes of Health, Bethesda, MD, USA). 
$m R N A$ extraction and RT-qPCR analysis. The total mRNA was isolated from rat ADSCs in the fourth passage using RNA Isolator Total RNA Extraction reagent (Vazyme, Piscataway, NJ, USA). The mRNA was detected using an Ace- $\mathrm{Hi}^{\mathrm{TM}}$ One Step Quantitative Real-Time PCR SYBR Green kit (cat. no. Q221-01; Vazyme) and RT-qPCR was performed using an LCS 480 real-time PCR system, according to the manufacturers' protocols. The primers were provided as follows: S-100, forward 5-CTTGATTTGCTTCAGGGA TGA-3 and reverse 5-CCCACAGAGTGTTGATTTCG-3; P75, forward 5-TTTGCTTGCTGTTGGAATGA-3 and reverse 5-ATGCTCCTGGTCTCTTCACC-3; GFAP, forward 5-GCT CCAAGATGAAACCAACC-3 and reverse 5-CCAGCGACT CAACCTTCCT-3); GAPDH, forward 5-GGA GCG TGG CTACTCTTTTG-3 and reverse 5-GGCTGGAAGAGTGTC TCAGG-3. The reaction conditions were as follows: Stage one, reverse transcription involving one cycle of $50^{\circ} \mathrm{C}$ for $30 \mathrm{~min}$; stage two, predegeneration involving one cycle of $95^{\circ} \mathrm{C}$ for $10 \mathrm{~min}$; stage three, cyclic reaction involving 40 cycles of $95^{\circ} \mathrm{C}$ for $10 \mathrm{sec}$ and $60^{\circ} \mathrm{C}$ for $30 \mathrm{sec}$; stage four, melting curve (one cycle, default). The relative expression value of each mRNA was calculated using the $2^{-\Delta \Delta C q}$ method (11), and normalized to that of GAPDH mRNA for each data point.

\section{Proliferation assay of Schwann-like cells}

3-(4,5-dimethyl-2-thiazolyl)-2,5-diphenyl-2H-tetrazolium bromide (MTT) assay. To assess cell proliferation, an MTT (Sigma-Aldrich) assay was performed. Briefly, following culture for 1, 3, 5, 7, 9 and 11 days, the Schwann-like cells were seeded into 96-well plates at a density of $2 \times 10^{4}$ cells $/ \mathrm{ml}$, and cultured for $24 \mathrm{~h}$ at $37^{\circ} \mathrm{C}$ in $5 \% \mathrm{CO}_{2}$. Subsequently, MTT ( $5 \mathrm{mg} / \mathrm{ml}, 20 \mu \mathrm{l} /$ well) was added at $37^{\circ} \mathrm{C}$ for $4 \mathrm{~h}$, following which the culture medium was carefully removed, and $150 \mu \mathrm{l}$ dimethyl sulfoxide was added to each well. The culture plate was then placed on a shaker and agitated at a low speed for $10 \mathrm{~min}$. The absorbance density of each well was measured using an enzyme-linked immunometric meter (Multiskan Ascent, Thermo Fisher Scientific, Inc.) at $490 \mathrm{~nm}$.

Observation and recording of the growth state of cells. The growth states of the Schwann-like cells were observed and recorded under an inverted microscope (BH2; Olympus Corporation, Tokyo, Japan) every day.

Statistical analysis. The experiments for each group were run in triplicate. Data were expressed as the mean \pm standard deviation. Statistical analysis was performed using SPSS 17.0 software (SPSS, Inc., Chicago, IL, USA). Student's paired-sample $t$-test was used for between-group comparisons of the means. One-way analysis of variance was used for the comparison of multiple groups. $\mathrm{P}<0.05$ was considered to indicate a statistically significant difference.

\section{Results}

ADSC isolation and identification. After $24 \mathrm{~h}$ primary culture, the rat ADSCs had adhered with a short spindle or polygonal shape (Fig. 1A), whereas at $72 \mathrm{~h}$, the cell density was increased, and fibroblast-like colonies had formed. After 1 week, the ADSCs exhibited a uniformly aligned monolayer of fibroblast-like cells, with a swirl or parallel growth style (Fig. 1B). Between the first and fifth passages, the growth of the ADSCs was marked. However, the cells appeared irregular and larger in size at passage 10, and showed reduced proliferation (Fig. 1C).

The multipotent differentiation characteristic was demonstrated by culturing the cells with osteogenic medium and adipogenic medium. As shown in Fig. 1D, a calcific knob was visualized following staining with Alizarin Red, and small adipose drops had gathered intracellularly, detected using Oil-Red O, as shown in Fig. 1E. As shown in Fig. 1F-H, the primary cultured ADSCs expressed positively for CD29 (99.3\%) and CD44 (94.3\%), but not for CD 49 (1.3\%), CD45 $(0.1 \%), \mathrm{CD} 106(0.0 \%)$ or CD $31(0.0 \%)$, indicating that the cells were MSCs, but were not from hematopoietic stem cells.

Induction of ADSCs to differentiate into Schwann-like cells. The rat ADSCs were treated with SC-conditioned medium for 12 days. At the beginning of differentiation, the morphology of the ADSCs changed from a monolayer of large cells with a flat morphology to a small number of bipolar or tripolar spindle-like shaped cells (Fig. 2A). As the cells continued to proliferate, the density of cells was markedly increased (Fig. 2B). The results of the immunofluorescence (Fig. 2C-E), western blot (Table I, Fig. 2F-I) and RT-qPCR (Fig. 2J) analyses showed that almost all the differentiated ADSCs were positive for GFAP, S100 and P75. These characteristics of differentiated ADSCs were similar to those of SCs.

Observation of the proliferation of Schwann-like cells. In the present study, the viability and proliferation of the Schwann-like cells were analyzed using an MTT assay. As shown in Fig. 3A, during the first 1-3 days, the cells grew slowly. The rate of cell proliferation increased more rapidly from day 3, and this rapid growth rate continued until day 7 . Between days 9 and 11, the cells continue to grow, however, the growth rate had declined. During the experiment, images were captured of mitosis in the Schwann-like cells in each period. The chromatin filament formed a spiral shape, resembling a loose knitting ball, during prophase of mitosis (Fig. 3B). During metaphase (Fig. 3C), the chromosomes arranged in order at the equator and, during anaphase (Fig. 3D), the two chromatids of each chromosome separated and moved in the opposite directions. The chromatids divided into two groups and the cells were elongated, exhibiting a dumbbell-like shape. In telophase (Fig. 3E), gradual unwinding of the chromatids was observed, with one cell dividing into two cells.

\section{Discussion}

Considerable attention has been focused on PNI due to its increased rate of morbidity. Once PNI occurs, the major physical response of the body is to protect the remaining neurons around the damage zone and restructure the axon (12). In previous studies of SCs, the glial cells of the peripheral nervous system, they were shown to be involved in nerve regeneration by secreting neurotrophic factors (13). However, Evans et al (14) demonstrated that the effects of SCs were also concentration-dependent and distance-dependent, with more marked regenerative effects on nerve degeneration with 

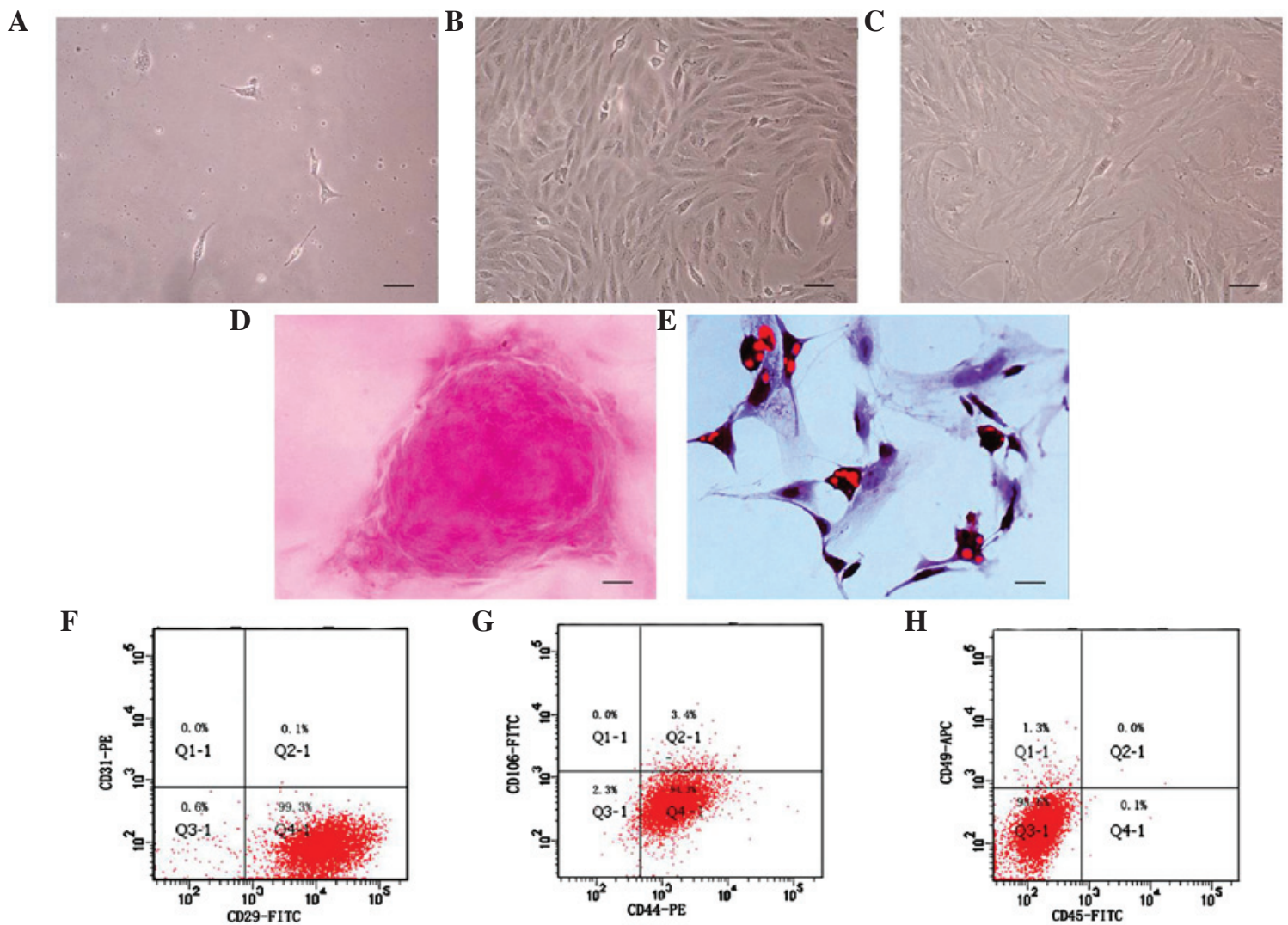

Figure 1. Isolation and identification of ADSCs. (A) Primary culture of ADSCs within $24 \mathrm{~h}$; (B) ADSCs in the fourth passage; (C) ADSCs following 10 passages. Scale bar=100 $\mu \mathrm{m}$. ADSCs were stained using (D) Alizarin Red and (E) Oil-Red O (magnification, x400). Scale bar=100 $\mu \mathrm{m}$. (F-H) Flow cytometric analysis of ADSCs. ADSCs, adipose-derived stem cells. FITC, fluorescein isothiocyanate; PE, phycoerythrin; APC, allophycocyanin.

increasing concentration in conduits, and a larger area of the distal axonal regeneration. Despite this, cultured SCs have limited clinical application, whereas stem cells are readily accessible as an alternative cell source for nerve regeneration.

It has been reported that MSCs can be readily derived from bone marrow for autologuous transplantation in in vitro (15) and in vivo (16) studies. Due to the complicated procurement and survival of SCs, this alternative cell source requires further investigation. ADSCs, which are isolated from adipose tissue, exhibit self-renewal and can differentiate along several mesenchymal tissue lineages, including adipocytes, osteoblasts, myocytes, chondrocytes and endothelial cells $(17,18)$. Liposuction is a common and safe surgical procedure, enabling a substantial number of cells to be obtained with minimal risk (19). Furthermore the ratio of ADSCs in adipose tissue is higher than that of BMMSCs, and ADSCs proliferate significantly more rapidly, compared with BMMSCs, Therefore, ADSCs may be an idea alternative cell source to SCs. It has also been reported that ADSCs can be induced into $\mathrm{SCs}$ in vitro (10).

The ADSCs used in the present study were obtained from the rat inguinal fat pad, and the cells in the third to fifth passages were positive for the expression of CD29 and CD44, whereas the expression of CD31 (an endothelial cell marker), CD45 (a hematopoietic cell marker) and CD106 (a marker of BMMSCs) were negative.

In addition to measurements of cell surface markers, whether ADSCs have the potential for multidirectional differentiation has also been investigated (20). Under the combined function of Vitamin $\mathrm{C}, \beta$-sodium glycerophosphate and hexadecadrol, the present study found the presence of a calcific knob, which stained red following Alizarin Red staining. This showed that calcification appeared during the induction of osteogenesis, with extracellular calcium ion deposition and the formation of calcium salt. No similar knobs were found in the contrasting group. Under the combined function of insulin, hexadecadrol, IBMX and indometacin, it was found that small adipose drops gathered, which appeared red on Oil-Red O staining. This was not observed in the contrasting group. All the above experiments demonstrated that the ADSCs exhibited osteogenic and adipogenic differentiation potential.

In the present study, ADSCs were induced and differentiated into Schwann-like cells with various cytokines. $\beta$-ME promotes neural differentiation in stem cells by preventing damage to cells of the peroxidase (21). The mechanism involves $\beta$-ME increasing the rate of synthesis of glutathione and reducing the cell response to oxygen tension (22). ATRT has an effect on the differentiation of neural stem cells through cell surface receptors, retinoic acid receptors and retinoid $\mathrm{X}$ receptors, and these can regulate the expression of certain coding factors, which are critical to the development of neural cell differentiation (23). HRG is a subtype of neuregulin, regarded as an important axonal signal, which can not only prevent apoptosis of SC precursors, but also induce neural crest differentiation into SCs selectively (24). Another study showed that HRG predominately acts on myelination (25). FSK can elevate the level of intracellular cAMP, and cAMP elevation can mimic SC responses in the presence of 
A

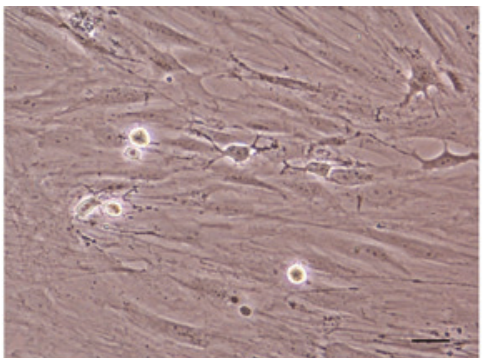

B

C

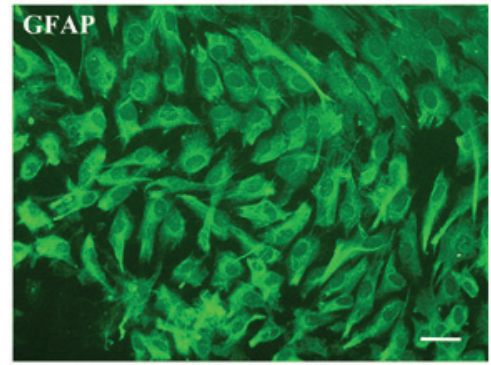

D

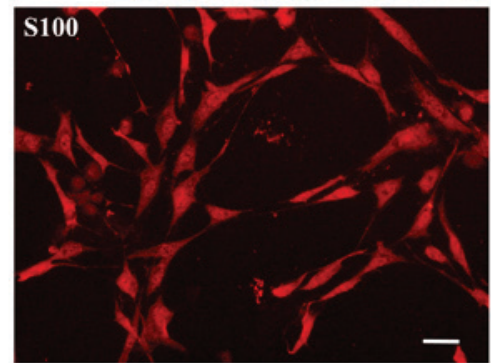

E
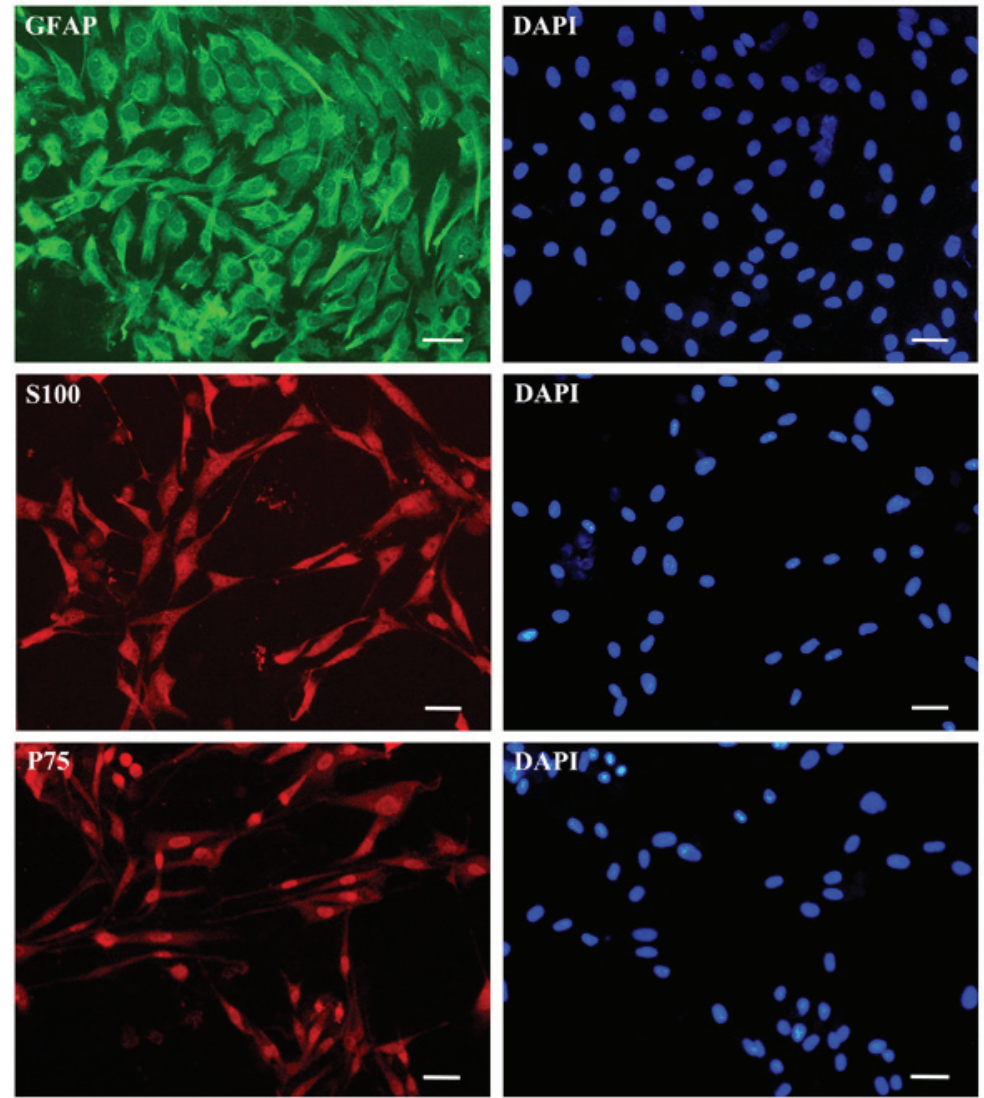

F

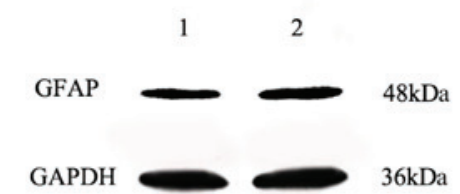

G

2

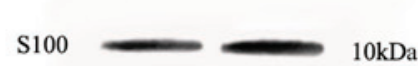

H
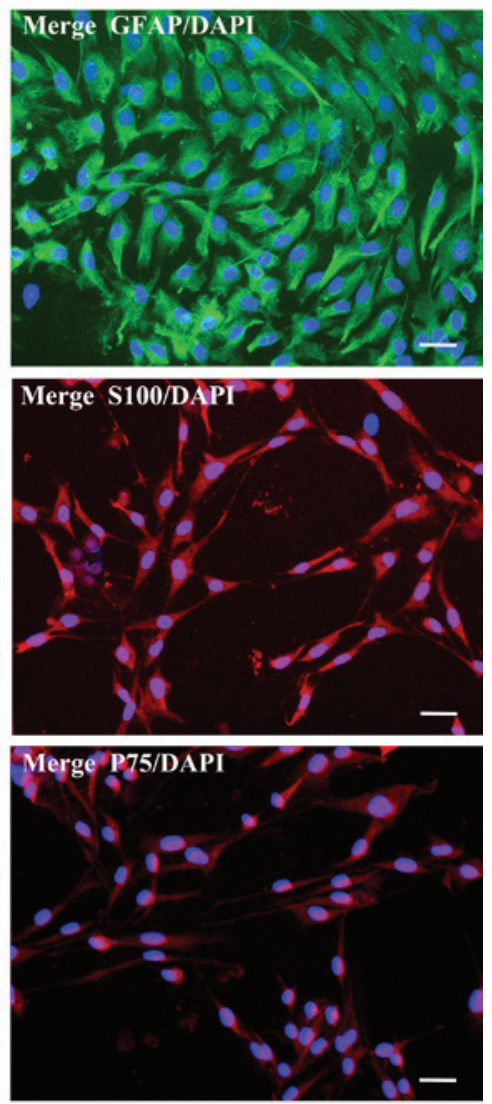

GAPDH

GAPDH

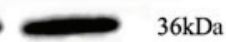

GAPDH

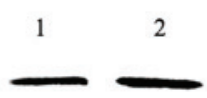

$42 \mathrm{kDa}$

I

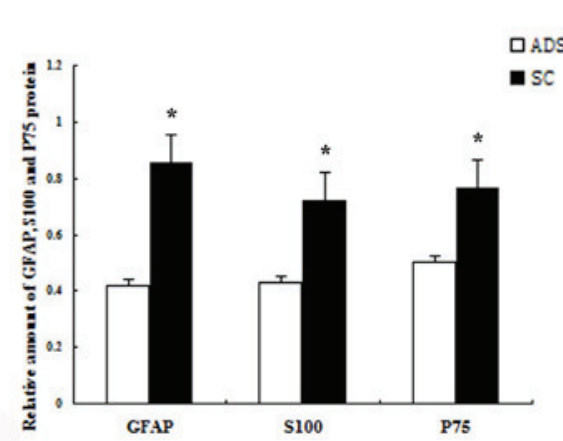

J

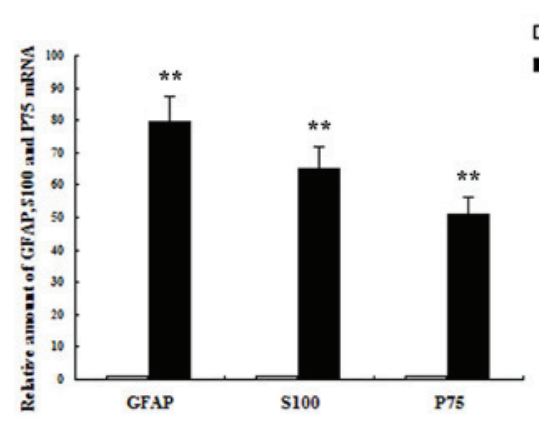

$\square A D S C$

- SC

Figure 2. ADSC differentiation into cells with an SC phenotype. (A) Cultured cells at the early stage of differentiation. (B) ADSCs differentiated into SC phenotype. Immunofluorescence staining of (C) GFAP, (D) S100 and (E) P75. Scale bar=100 $\mu$ m. Cell nuclei were labeled with DAPI (blue). Detection of (F) GFAP, (G) S100 and (H) P75 proteins using western blot analysis. (I) Relative protein expression levels of GFAP, S100 and P75 ("P<0.05, vs. ADSCs). 1, ADSCs, 2, Schwann-like cells. (J) Detection of mRNA expression levels of GFAP, S100 and P75 using reverse transcription-quantitative polymerase chain reaction analysis $\left({ }^{* *} \mathrm{P}<0.01\right.$, vs. ADSCs). Values are presented as the mean \pm standard deviation. SC, Schwann cell; ADSCs, adipose-derived stem cells; GFAP, glial fibrillary acidic protein. 
Table I. Protein expression levels of GFAP, S100 and P75.

\begin{tabular}{llll}
\hline Group & GFAP & S100 & P75 \\
\hline Adipose-derived stem cells & $0.417 \pm 0.076$ & $0.502 \pm 0.150$ & $0.431 \pm 0.155$ \\
Schwann-like cells & $0.613 \pm 0.063^{\mathrm{a}}$ & $0.766 \pm 0.134^{\mathrm{a}}$ & $0.721 \pm 0.171^{\mathrm{a}}$ \\
\hline
\end{tabular}

Values are presented as the mean \pm standard deviation. ${ }^{\mathrm{a}}<0.05$, vs. adipose-derived stem cells; GFAP, glial fibrillary acidic protein.

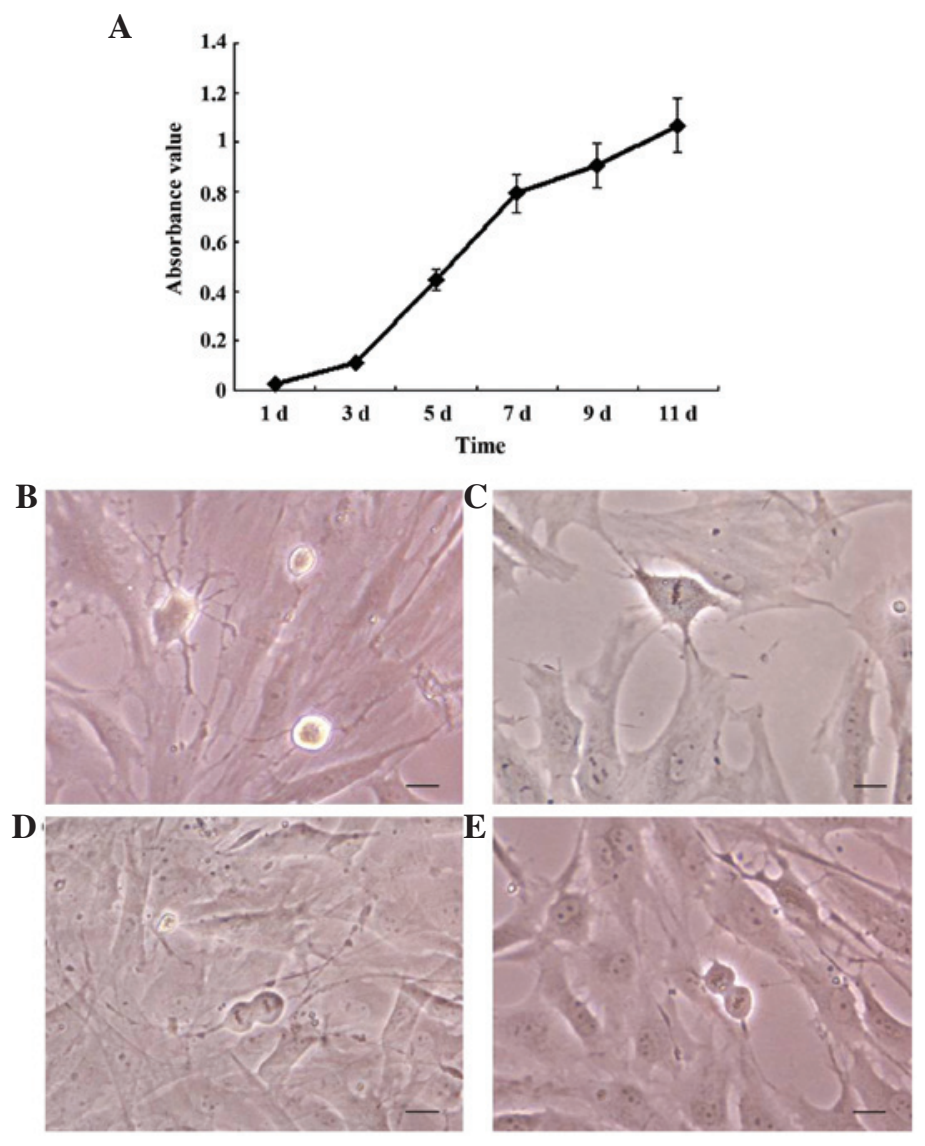

Figure 3. Analysis of the proliferation of Schwann-like cells. (A) a 3-(4,5-dimethyl-2- thiazolyl)-2,5-diphenyl-2H-tetrazolium bromide assay was used to examine the growth rate of Schwann-like cell populations following differentiation for 1, 3, 5, 7,9 and 11 days. Values are presented as the mean \pm standard deviation of triplicate experiments. Images of mitosis of the Schwann-like cells in (B) prophase, (C) metaphase, (D) anaphase and (E) telophase. Scale bar $=100 \mu \mathrm{m}$.

axons during myelination in vivo (26). bFGF has been reported to be involved in cell growth and differentiation. Zhu et al (25) demonstrated that bFGF is a major regulator for MSC differentiation into the SC phenotype.

In the present study, immunofluorescence revealed that bipolar, tripolar and even multipolar cells were positive for GFAP, S-100 and P75. To confirm that the results obtained using immunofluorescence were not due to any artefact of cell shrinkage, western blot and RT-qPCR analyses were performed. The Schwann-like cells showed GFAP, S-100 and P75 immunoreactive bands, corresponding to molecular weights of 48,10 and $42 \mathrm{kDa}$ respectively. The results of the RT-qPCR, probed with GFAP, S-100 and P75 primers, also supported the results of the immunofluorescence and western blot analyses. In addition, a previous study showed that this differentiation was lasting and irreversible (27).
In addition, the morphological and phenotypic characteristics did not posses the functions of SCs derived from adipose cells, thus, the present study observed the mitosis of the Schwann-like cells, which increased the numbers of cells in cascades. The results showed that the Schwann-like cells were fully confluent in a short duration once attached, which is beneficial for clinical regeneration following PNI. As for the specific mechanism underlying Schwann-like cell mitotic proliferation, it may be associated with cross-talk between the two cell types by soluble secreted proteins (28), which requires further investigation. The present study hypothesized that this may be associated with activation of the mitogen-activated protein kinase/extracellular signal-regulated kinase signaling pathway and/or inhibition of the caspase pathway, which requires investigation in subsequent experiments. Due to the limitations on research funds and time in the present study, 
only the mitosis of Schwann-like cells derived from ADSCs were observed. Whether SCs cultured directly from the sciatic nerve or brachial nerve, or from BMMSCs can perform mitosis remains to be elucidated and warrants further investigation to determine their potential benefit. The present study provides broad information that may aid the future development of cell therapy in PNI.

\section{Acknowledgements}

This study was supported by the Science and Technology Department of Liaoning Province (grant no. 2013225049) and the Education Department of Hebei Province (grant no. QN2014138).

\section{References}

1. Zhang P, Lu X, Chen J and Chen Z: Schwann cells originating from skin-derived precursors promote peripheral nerve regeneration in rats. Neural Regen Res 9: 1696-1702, 2014.

2. Nishihara T, Remacle AG, Angert M, Shubayev I, Shiryaev SA, Liu H, Dolkas J, Chernov AV, Strongin AY and Shubayev VI: Matrix metalloproteinase-14 both sheds cell surface neuronal glial antigen 2 (NG2) proteoglycan on macrophages and governs the response to peripheral nerve injury. J Biol Chem 290: 3693-3707, 2015.

3. Fairbairn NG, Meppelink AM, Ng-Glazier J, Randolph MA and Winograd JM: Augmenting peripheral nerve regeneration using stem cells: A review of current opinion. World J Stem Cells 7: 11-26, 2015.

4. Berrocal YA, Almeida VW, Gupta R and Levi AD: Transplantation of Schwann cells in a collagen tube for the repair of large, segmental peripheral nerve defects in rats. J Neurosurg 119: 720-732, 2013.

5. Gärtner A, Pereira T, Armada-da-Silva P, Amado S, Veloso A Amorim I, Ribeiro J, Santos J, Bárcia R, Cruz P, et al: Effects of umbilical cord tissue mesenchymal stem cells (UCX®) on rat sciatic nerve regeneration after neurotmesis injuries. J Stem Cells Regen Med 10: 14-26, 2014.

6. Park HW, Lim MJ, Jung H, Lee SP, Paik KS and Chang MS: Human mesenchymal stem cell-derived Schwann cell-like cells exhibit neurotrophic effects, via distinct growth factor production, in a model of spinal cord injury. Glia 58: 1118-1132, 2010.

7. Dadon-Nachum M, Sadan O, Srugo I, Melamed E and Offen D: Differentiated mesenchymal stem cells for sciatic nerve injury. Stem Cell Rev 7: 664-671, 2011.

8. Sabatino MA, Santoro R, Gueven S, Jaquiery C, Wendt DJ, Martin I, Moretti M and Barbero A: Cartilage graft engineering by co-culturing primary human articular chondrocytes with human bone marrow stromal cells. J Tissue Eng Regen Med 9: 1394-1403, 2015.

9. Liu Y, Zhang Z, Qin Y, Wu H, Lv Q, Chen X and Deng W: A new method for Schwann-like cell differentiation of adipose derived stem cells. Neurosci Lett 551: 79-83, 2013.

10. Razavi S, Mardani M, Kazemi M, Esfandiari E, Narimani M, Esmaeili A and Ahmadi N: Effect of leukemia inhibitory factor on the myelinogenic ability of Schwann-like cells induced from human adipose-derived stem cells. Cell Mol Neurobiol 33: 283-289, 2013.

11. Esmaeili A and Zaker SR: Differential expression of glycine receptor subunit messenger RNA in the rat following spinal cord injury. Spinal Cord 49: 280-284, 2011.

12. Liu Y, Nie L, Zhao H, Zhang W, Zhang YQ, Wang SS and Cheng L: Conserved dopamine neurotrophic factor-transduced mesenchymal stem cells promote axon regeneration and functional recovery of injured sciatic nerve. PLoS One 9: e110993, 2014.
13. Jonsson S, Wiberg R, McGrath AM, Novikov LN, Wiberg M, Novikova LN and Kingham PJ: Effect of delayed peripheral nerve repair on nerve regeneration, Schwann cell function and target muscle recovery. PLoS One 8: e56484, 2013.

14. Evans GR, Brandt K, Katz S, Chauvin P, Otto L, Bogle M, Wang B, Meszlenyi RK, Lu L, Mikos AG and Patrick CW Jr: Bioactive poly (L-lactic acid) conduits seeded with Schwann cells for peripheral nerve regeneration. Biomaterials 23: 841-848, 2002.

15. Wang $\mathrm{H}$, Zhang $\mathrm{H}$, Liu $\mathrm{M}$ and Wang N: Distal segment extracts of the degenerated rat sciatic nerve induce bone marrow stromal cells to express Schwann cell markers in vitro. Neurosci Lett 544: 89-93, 2013.

16. Ladak A, Olson J, Tredget EE and Gordon T: Differentiation of mesenchymal stem cells to support peripheral nerve regeneration in a rat model. Exp Neurol 228: 242-252, 2011.

17. Ferroni L, Gardin C, Tocco I, Epis R, Casadei A, Vindigni V, Mucci G and Zavan B: Potential for neural differentiation of mesenchymal stem cells. Adv Biochem Eng Biotechnol 129: 89-115, 2013.

18. Ghidoni I, Chlapanidas T, Bucco M, Crovato F, Marazzi M, Vigo D, Torre ML and Faustini M: Alginate cell encapsulation: New advances in reproduction and cartilage regenerative medicine. Cytotechnology 58: 49-56, 2008.

19. Harasymiak-Krzyżanowska I, Niedojadło A, Karwat J, Kotuła L, Gil-Kulik P, Sawiuk M and Kocki J: Adipose tissue-derived stem cells show considerable promise for regenerative medicine applications. Cell Mol Biol Lett 18: 479-493, 2013.

20. Hagmann S, Moradi B, Frank S, Dreher T, Kämmerer PW, Richter W and Gotterbarm T: FGF-2 addition during expansion of human bone marrow-derived stromal cells alters MSC surface marker distribution and chondrogenic differentiation potential. Cell Prolif 46: 396-407, 2013.

21. Reid AJ, Sun M, Wiberg M, Downes S, Terenghi G and Kingham PJ: Nerve repair with adipose-derived stem cells protects dorsal root ganglia neurons from apoptosis. Neuroscience 199: 515-522, 2011.

22. Barnabé GF, Schwindt TT, Calcagnotto ME, Motta FL, Martinez G Jr, de Oliveira AC, Keim LM, D'Almeida V, Mendez-Otero R and Mello LE: Chemically-induced RAT mesenchymal stem cells adopt molecular properties of neuronal-like cells but do not have basic neuronal functional properties. PLoS One 4: e5222, 2009.

23. Lainey E, Wolfromm A, Sukkurwala AQ, Micol JB, Fenaux P, Galluzzi L, Kepp O and Kroemer G: EGFR inhibitors exacerbate differentiation and cell cycle arrest induced by retinoic acid and vitamin D3 in acute myeloid leukemia cells. Cell Cycle 12: 2978-2991, 2013.

24. Lee HJ, Shin YK and Park HT: Mitogen activated protein kinase family proteins and c-jun signaling in injury-induced Schwann cell plasticity. Exp Neurobiol 23: 130-137, 2014.

25. Zhu H, Yang A, Du J, Li D, Liu M, Ding F, Gu X and Liu Y: Basic fibroblast growth factor is a key factor that induces bone marrow mesenchymal stem cells towards cells with Schwann cell phenotype. Neurosci Lett 559: 82-87, 2014

26. Guo L, Moon C, Niehaus K, Zheng Y and Ratner N: Racl controls Schwann cell myelination through cAMP and NF2/merlin. J Neurosci 32: 17251-17261, 2012.

27. Li P, Sun H, Du M, Fa Z, Qin K, Xu W, Zhang R, Chen L, Yao C, Xiao Z, et al: Adult rat hippocampus soluble factors: A novel transplantation model mimicking intracranial microenvironment for tracing the induction and differentiation of adipose-derived stromal cells in vitro. Neurosci Lett 542: 5-11, 2013.

28. Wei Y, Gong K, Zheng Z, Liu L, Wang A, Zhang L, Ao Q, Gong Y and Zhang X: Schwann-like cell differentiation of rat adipose-derived stem cells by indirect co-culture with Schwann cells in vitro. Cell Prolif 43: 606-616, 2010. 